rate and tidal volume. The descending limbic pathways were, apparently, not interrupted and emotional stimuli led to modulation of automatic respiration. Automatic respiratory control was, in turn, disrupted by the bilateral pontine lesions and this led to the development of apneustic breathing. The most striking feature of the apneustic pattern was that the

1 Plum F. Neurological integration of behavioural and metabolic control of breathing. In: Parker R, ed. Breathing: Hering-Breuer centenary symposium. London: Churchill 970; pp 314-27.

2 Howard RS, Newsom Davis J. The neural control of respiratory function. In: Crockard A, Hayward R, Hoff TT. eds Neurosurgery - the scientific basis of clinical practice Oxford: Blackwell Scientific Publications 1992; pp 318-36.

3 Munschauer FE, Mador MJ, Ahuja A, Jacobs L. Selective paralysis of voluntary but not limbically influenced automatic respiration. Arch Neurol 1991; 48: 1190-2.

4 Dawson K, Hourihan MD, Wiles CM, Chawla JC. Separation of voluntary and limbic activation of facial and respiratory muscles in ventral pontine infarction. $₹$ Neurol Neurosurg Psychiatry 1994; 57: 1281.

5 Heywood P, Howard RS, Murphy K, Corfield D, Morrell M, Guz A. Control of respiration in the 'locked in syndrome'. F Neurol Neurosurg Psychiatry 1994; 57: 1293. inspiratory spasms could only be precipitated by emotional outburst. This finding would support the view that the descending limbic pathway directly influences automatic respiratory control. It also demonstrates that emotional input may precipitate apneustic respiration in the presence of disrupted automatic control due to pontine disease.

6 Topper R, Kosinski C, Mull M. Volitional type of facia palsy associated with pontine ischaemia. $\mathcal{F}$ Neurol Neurosurg Psychiatry 1995; 58: 732-4

7 Van Gijn J. Treating uncontrolled crying after stroke. Lance 1993; 48: $1190-2$.

8 Plum F, Alvord EC. Apneustic breathing in man. Arch Neurol 1964; 10: 101-12.

9 Howard RS, Wiles CM, Hirsch NP, Loh L, Spencer GT, Newsom Davis J. Respiratory involvement in multiple sclerosis. Brain 1992; 115: 479-94.

10 Besson G, Bogousslavsky J, Regli F, Maeder P. Acute pseudobulbar or suprabulbar palsy. Arch Neurol 1991; 48: 501-7.

11 Plum F, Posner JR. Diagnosis of stupor and coma. Philadelphia: FA Davis, 1983.

\title{
Syncope: driving advice is frequently overlooked
}

\author{
M MacMahon, D O’Neill, R A Kenny
}

\begin{abstract}
Summary
Consecutive referrals to a syncope clinic were asked about the frequency of enquiries about driving status by referring general practitioners and/or hospital specialists. Although $40 \%$ were drivers, only $13 \%$ of patients had been previously asked about driving, and $12 \%$ of drivers had experienced symptoms whilst driving. This represents an important oversight on the part of referring doctors.
\end{abstract}

Keywords: syncope, driving

Cardiovascular

Investigation Unit,

Department of

Medicine (Geriatric),

Royal Victoria

Infirmary, Newcastle

Upon Tyne NE1 4LP,

UK

M MacMahon

RA Kenny

Age-Related Health

Care, Meath Hospital,

Dublin 8, Ireland

D O'Neill

Correspondence to

Dr RA Kenny

Accepted 3 January 1996
Drivers who suffer from recurrent syncope may be a hazard on the road, yet the importance of syncope as a cause of driving accidents has received little attention in the literature. ${ }^{1,2}$ In the UK, it is the patient's responsibility to notify the Driving and Vehicle Licensing Agency (DVLA) if they have experienced an episode of loss of consciousness. ${ }^{3}$ Doctors should advise their patients of this. ${ }^{4}$ The DVLA may approach the attending physician for a report once the patient's consent has been obtained. A licence may be issued if the disorder can be controlled. ${ }^{4}$ Attending physicians are often unclear about their responsibilities in reporting syncope or advising about syncope and driving and physicians generally have scant knowledge of medical regulations on driving. ${ }^{2}$ Our objective was to determine how often patients with recurrent syncope were asked about driving status by either general practitioners or hospital specialists.

\section{Methods and results}

Consecutive referrals to the syncope clinic during a two-month period all completed a semi-structured questionnaire. Patients were asked about the frequency of enquiries about driving status by referring general practitioners and/or hospital specialists. Patients were also asked about their driving status and whether they considered that they were safe to drive. Presenting symptoms and their attributable causes were also detailed.

Sixty-four referrals were studied: median age 72 years (range 21 to 91 years), 34 male. All were secondary or tertiary referrals. Symptoms had been present for an average of four years (range one month to four years) with an

Hospital specialists who had investigated patients for symptoms of syncope

- general physicians $58 \%$

- cardiologists $27 \%$

- ear, nose and throat surgeons $9 \%$

- neurologists $4 \%$

- psychiatrists $2 \%$ 
average of 16 episodes (range one to 100 episodes). Only $13 \%$ had been previously questioned about driving. Those not asked included two drivers of heavy goods vehicles (34 and 43 years old, respectively). All patients had been reviewed for symptoms of syncope by a general practitioner. In addition, 60 patients had been reviewed on one or more occasions by hospital specialists (box).

Twenty-five patients (40\%) were drivers; mean age 62 years. All experienced syncope Only 12 drivers had experienced a prodrome prior to syncope; in five, symptoms occurre during head-turning or whilst sitting. In tw

Table DVLA recommendations for cardiovascular syncope (adapted, with permission, from ref 3).

\begin{tabular}{|c|c|}
\hline Cardiovascular disorder & Group 1 entitlement \\
\hline $\begin{array}{l}\text { Arrhythmia } \\
\text { Including any significant } \\
\text { disturbance of cardiac rhythm, } \\
\text { ie, bradycardia due to } \\
\text { atrioventricular block (including } \\
\text { congenital heart block) or sinus } \\
\text { node disease; or a supraventricular } \\
\text { (including atrial flutter and } \\
\text { fibrillation), junctional or } \\
\text { ventricular tachyarrhythmia } \\
\text { NB Transient arrhythmias }\end{array}$ & $\begin{array}{l}\text { Driving must cease with an } \\
\text { arrhythmia which may distract the } \\
\text { driver's attention or render him/he } \\
\text { liable to sudden impairment of } \\
\text { cerebral function. Driving will be } \\
\text { permitted when satisfactory control } \\
\text { of symptoms is achieved. Short } \\
\text { period licence subject to regular } \\
\text { medical review for patients with } \\
\text { history of idiopathic ventricular } \\
\text { tachyarrhythmia }\end{array}$ \\
\hline
\end{tabular}
occurring within the acute phase of a coronary event or heart surgery normally will not debar and the recommendations for arrhythmia for Group 1 and 2 entitlement therefore do not apply to events in

Licence retained till 70 (ventricular tachyarrhythmia excepted) provided there are no other disqualifying conditions
Malignant vasovagal syndrome and cardiogenic symcope

Simple syncopal attack(s) physiologically provoked and postural hypotension

Drug treatment - side-effects from medication likely to impair driving performance
Cases individually considered by DVIA

Need not be notified and driving need not cease if not associated with heart disease

If causes symptoms which will affect driving ability or sudden and disabling vertigo or syncope, driving must cease until satisfactory control of symptoms achieved
Loss(es) of consciousness in which investigations have not revealed a cause, ie, there is an open-ended liability for recurrence, and the cause is unexplained
With a single episode at least one year off driving with freedom from such attacks during this period. Review licence for $1 / 2 / 3$ years. Retained till 70 after 4 years free (ie, treated as for solitary fit)
Group 2 entitlement

Recommended refusal or revocation if persistent or recurren arrhythmia or conduction defect within the past 5 years and has caused within the past 2 years or is likely to cause sudden impairment of consciousness or distracts the driver's attention. If the arrhythmis does not cause such symptoms, mał. be licensed if there is no significan $N$ structural cardiac abnormality, ie, o no documented significant echocardiographic abnormality is ir present, and exercise testing can be completed as per national guidelines. In exercise testing for arrhythmias medication need not be discontinued before test is undertaken

Medication prescribed to control o@ prevent the arrhythmia is not a bar, provided it does not cause symptoms likely to impair driver's? performance (see Drug treatment).

Where rhythm disturbance is treated by aberrant pathway ablation relicensing may occur 3 months after procedure provided: no recurrence and no antiarrhythmic medication required and no other disbarring aspect/condition is present.

Cases individually considered by DVLA

As for Group 1

Applicants or licence holders suffering symptoms causing or likely to cause sudden impaired consciousness or significant constitutional symptoms should be $N$ regarded temporarily unfit until the symptoms have completely resolved. If symptoms are likely to be recurrent or permanent, recommended refusal or revocations

Recommended refusal or revocation. After 5 years freedom from such episodes, specialist assessment may be undertaken to decide when driving may restart \\ tots

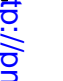

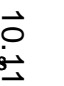

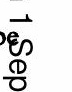

족.


patients, symptoms occurred when driving and one was involved in a fatal motor accident. Most (84\%) drivers considered themselves safe to drive and $88 \%$ reported that driving was important to them.

The attributable diagnoses in drivers were carotid sinus syndrome in 10 patients (cardioinhibitory in seven and mixed cardioinhibitory or vasodepressor in three), vasovagal syncope (seven patients), atrioventricular block, ventricular tachycardia, orthostatic hypotension, and epilepsy (one each), while in four patients the syncope was unexplained.

\section{Comment}

Although $40 \%$ of patients attending a syncope clinic were drivers, only $13 \%$ had been previously asked about driving and $12 \%$ of drivers had experienced symptoms whilst driving. This represents an important oversight on the part of referring doctors.

Attending physicians are often unclear about their responsibilities in reporting such attacks, and about the advice they should give to patients on when to report symptoms and when to drive (table). ${ }^{1}$ Doctors in the UK should advise patients with syncope to inform the DVLA and should document such discus-

1 Spudis EV, Penry JK, Gibson P. Driving impairment caused by episodic brain dysfunction. Restrictions for epilepsy and syncope. Arch Neurol 1986; 43: 558-64.

2 O'Neill D, Crosby T, Shaw A, Haigh R, Hendra TJ. Fitness to drive in the older patients: awareness among hospital to drive in the older patients: aware
physicians. Lancet 1994; 344: 1366-7.

3 Taylor JF, ed. Medical aspects of fitness to drive - a guide for

Taylor JF, ed. Medical aspects of fitness to drive - a guide for
medical practitioners. The Medical Commission on Accident Prevention. Swansea: DVLA, 1995. sions. Direct contact with the DVLA is only allowed if there is evidence of continued driving which constitutes a hazard to others. This contrasts with the position in the USA and certain provinces in Canada where the doctor is bound by law to report patients to the licensing authorities. Compliance of patients with reporting requirements to the licensing authorities is also a problem. There is evidence that a significant proportion of patients with epilepsy have driven illegally and have failed to inform the licensing agency. ${ }^{5}$ Certain insurance companies will abrogate responsibility for damages in accidents involving individuals who fail to report their medical condition. This information should be given to patients when advising about driving.

Advice is not always negative. A diagnosis can be made in many patients with syncope and, after appropriate intervention, patients may resume driving. For syncope which remains unexplained, at least one year off driving with freedom from attacks (for a single episode) or five years off driving with freedom from attacks (for recurrent episodes), is recommended. ${ }^{4}$

Thus, general practitioners and hospital doctors should routinely ask patients with syncope about driving status and provide advice appropriate to the current guidelines.

4 Irvine J, Petch M. Fitness to drive: update guidelines for cardiovascular fitness in vocational drivers. Health Trends 1994; 26: 38-40.

5 Dickey W, Morrow JI. Epilepsy and driving: attitudes and practices among patients attending a seizure clinic. $\mathcal{J} R$ Soc Med 1986; 10: 566-8. 